\title{
Oxygen reduction reaction on silver electrodes under strong alkaline conditions
}

\author{
Saikrishnan Kandaswamy ${ }^{\mathrm{a}}$, Antonio Sorrentino ${ }^{\mathrm{a}}$, Shivangi Borate ${ }^{\mathrm{b}}$, Luka A. \\ Živkovićc ${ }^{\text {, Menka Petkovska }}{ }^{\mathrm{c}}$, Tanja Vidaković-Koch ${ }^{\mathrm{a}, *}$ \\ ${ }^{a}$ Max Planck Institute for Dynamics of Complex Technical Systems, Sandtorstr. 1, 39106 \\ Magdeburg, Germany. \\ ${ }^{b}$ Otto von Guericke University, Universitätsplatz 2, 39106 Magdeburg, Germany. \\ ${ }^{c}$ Faculty of Technology and Metallurgy, University of Belgrade, Karnegijeva 4, Serbia.
}

\begin{abstract}
Oxygen reduction reaction (ORR) was studied on a silver polycrystalline electrode in different $\mathrm{NaOH}$ concentrations with a help of rotating disc and rotating ring disc electrodes. Soluble reaction intermediate was detected at all alkaline concentrations, but its concentration increased with an increase of the level of impurities. ORR is not $\mathrm{NaOH}$ concentration dependent at low concentrations $(0.1$ and $1 \mathrm{M})$. In $11 \mathrm{M} \mathrm{NaOH}$ ORR onsets at more positive potentials in the region where underpotential silver oxide formation shows less reversible behaviour. The nonlinear frequency response analysis spectra show significant qualitative difference with $\mathrm{NaOH}$ concentration indicating a high capability of this method for kinetic mechanism investigations.

Keywords: oxygen reduction reaction, polycrystalline silver, rotating ring disc electrode, hydrogen peroxide, nonlinear frequency response analysis
\end{abstract}

\section{Introduction}

Oxygen reduction reaction (ORR) has high relevance for the development of different technical processes, like energy conversion processes in fuel cells, and recently batteries, as well as, some electrolysis processes. Due to its complex 5 kinetics, which involves the exchange of 2-4 electrons and different adsorption

\footnotetext{
* Corresponding author

Email address: vidakovic@mpi-magdeburg.mpg.de (Tanja Vidaković-Koch )
} 
steps it is often the major source of performance loss, reducing significantly, the overall efficiency of these processes. For this reason, ORR is very well studied in literature and there are numerous studies on different aspects of this reaction under different $\mathrm{pH}$ conditions, temperatures and on different catalysts, mainly platinum [1, 2]. Due to high interest in the development of polymer electrolyte fuel cell, most studies still refer to ORR under strongly acidic conditions and ORR under alkaline conditions is, in general, less studied. In this respect only a few studies in highly concentrated alkaline solutions on silver electrodes were reported [3, 4]. However, these conditions are hugely relevant for a technical process of chlorine production. In a so-called chlor-alkali electrolysis with oxygen depolarized cathode (ODC), ORR takes place on silver gas diffusion electrode (GDE) in ca. 30 wt \% NaOH. In such highly concentrated alkaline solutions, due to salt-out effect, oxygen solubility drops significantly down and it is almost 100 times lower than in $0.1 \mathrm{M} \mathrm{NaOH}$ (please see Table 1 for more detailed information). The highly concentrated alkaline solution has not only an effect on oxygen solubility but also on oxygen diffusivity. Both effects advise an appearance of strong mass transfer limitations in the technical electrodes and pose certain restrictions on liquid and gas phase distributions in porous gasdiffusion electrodes or imply the use of pure oxygen (instead of air) in order to 25 achieve technical current densities at reasonable overpotentials under industrial conditions [5]. Theoretical calculations by Pinnow et al [5] based on a thin-film layer agglomerate model, show that the thickness of liquid film has to be only ca. $60 \mathrm{~nm}$ in order to satisfy oxygen flux required to sustain ORR at technical current densities. The same group has shown that the thickness of the reaction zone based on simulations is only ca. $20 \mu \mathrm{m}$. Keeping in mind that amount of silver catalyst in technical electrodes is quite significant and that the thickness of technical electrodes is in mm range, the question is if the catalyst cost can be reduced without compromising electrode activity. In this respect in addition to oxygen solubility and diffusivity, it is interesting to know, how other parameters 35 related to ORR kinetics influence the reaction rate.

At the moment very little is known about ORR on silver at high alkaline 
concentrations. Chatenet et al. 3] studied ORR on a polycrystalline Ag electrode and an $\mathrm{Ag} / \mathrm{C}$ electrode under stationary conditions. The apparent kinetic parameters (exchange current density and Tafel slopes) were determined under 40 different operating conditions ( $\mathrm{NaOH}$ concentration (0.1-11.1 M) and temperatures $\left.\left(25-80^{\circ} \mathrm{C}\right)\right)$. The authors reported an increase of apparent exchange current density with $\mathrm{NaOH}$ concentration on $\mathrm{Ag} / \mathrm{C}$ electrodes. The Tafel slope values in $1 \mathrm{M} \mathrm{NaOH}$ were ca. $74 \mathrm{mV} \cdot \mathrm{dec}^{-1}$ and not very temperature dependent, while the Tafel slope value in $11 \mathrm{M}$ solution was ca. $44 \mathrm{mV} \cdot \mathrm{dec}^{-1}$. The authors 45 reported on only one Tafel slope region. In contrast to this study Pinnow et al. [5] in their theoretical study required two different Tafel slopes (ca. $80 \mathrm{mV} \cdot \mathrm{dec}^{-1}$ at low overpotentials and ca. $200 \mathrm{mV} \cdot \mathrm{dec}^{-1}$ at high overpotentials) in order to describe polarization curve for ORR on GDE. Chatenet et al. [3] assumed that ORR at high alkaline concentrations is $4 \mathrm{e}^{-}$process without significant peroxide 50 formation. In another study, Adanuvor et al. 4 studied ORR in $6.5 \mathrm{M}$ alkaline solutions. Interestingly they reported polarization curves with two plateaus, which they assigned to $2 \mathrm{e}^{-}$and $4 \mathrm{e}^{-}$ORR. In this study, peroxide formation was also not monitored. In view of previous studies an interesting question is if significant amounts of hydrogen peroxide are formed in ORR in highly concentrated alkaline solutions, and how this might potentially affect so-called three-phase interface in GDEs.

Having in mind that hydrogen peroxide might not be observed in experiments with GDE, the main goal of the present contribution is to study the kinetics of ORR in highly concentrated alkaline solutions on a smooth polycrystalline silver electrode. In order to check the possible formation of soluble intermediates of ORR, rotating ring disc electrode was used. Additionally, kinetics of ORR in alkaline solutions of lower concentrations was studied. In addition to cyclic voltammetry and quasi-stationary characterizations, nonlinear frequency response analysis was used to study ORR on silver in different concentrations 65 of $\mathrm{NaOH}$. 


\section{Experimental}

Sodium hydroxide of two different purities was used (sodium hydroxide monohydrate 99.99 \% Suprapur ${ }^{\circledR}$ Merck - B1491866739, referred in the text as pure and sodium hydroxide $99 \%$ Carlroth-9356.3, referred in the text as $\mu \mathrm{S} . \mathrm{cm}^{-1}$ ). Electrolyte solutions were saturated either with argon (Linde plc, purity grade 5.0) or oxygen (Linde plc, purity grade 5.0) gasses without further purification. All electrochemical tests were performed in three compartment Teflon cell. The counter electrode compartment was separated by Nafion mem$\mathrm{GmbH}$, Germany) was connected to the working electrode compartment via a Luggin capillary (made of PEEK). Platinum wire was used as a counter electrode and Pine Instrument Company's silver rotating disc or rotating ring disc electrodes attached to a Pine AFMSRCE rotator as working electrodes (WE). POLISH Pine Research) followed by 2 minutes sonication in ultra-sonic bath (Sonorex RK31, Bandelin electronic GmbH \& Co. KG). This procedure was repeated by polishing with $0.05 \mu \mathrm{m}$ alumina suspension (AK POLISH Pine Research) and 2 minutes sonication. After that the electrode was cycled in prereduced electrode [6]). Electrochemical experiments were performed with Solartron Energy Lab XM potentiostat (CV and nonlinear frequency response measurements) or Ivium compactstat (disc and ring current measurements). The experimental first and second order frequency response functions were calculated based on procedure described in [7. Nonlinear frequency response spectra were collected in frequency range from $19 \mathrm{kHz}$ to $0.059 \mathrm{~Hz}$ with $30 \mathrm{mV}$ root mean square (rms) amplitude. For determinations of oxygen reduction reaction intermediate product the potential of the ring electrode was set at $1.2 \mathrm{~V}$. 


\section{Results and Discussions} tential region below bulk silver oxide formation was recorded with a sweep rate of $200 \mathrm{mV} \cdot \mathrm{s}^{-1}$ (Figure $1 \mathrm{a}$ ) in $\mathrm{NaOH}$ at three different concentrations (0.1 M, $1 \mathrm{M}$ and $11 \mathrm{M})$. The $\mathrm{CV}$ in $11 \mathrm{M} \mathrm{NaOH}$ displays three pairs of peaks, a very broad one (I) at ca. $0.1 \mathrm{~V}$, a large one (II) at ca. $0.5 \mathrm{~V}$ and a small one (III) at

underpotential Ag oxides [8. The CVs of single crystal electrodes [9, similar to polycrystalline silver 8 show, at the most negative potentials, almost flat pro- 
files corresponding to charging/discharging of an electrochemical double layer, followed by the appearance of two pairs of reversible peaks. The peak potential and the broadness were single crystal surface dependent. For example, the peaks at more negative potentials are centered at ca. $0.0 \mathrm{~V}, 0.13 \mathrm{~V}$ and $0.3 \mathrm{~V}$ for $\mathrm{Ag}(110), \operatorname{Ag}(100)$ and $\mathrm{Ag}(111)$ single crystal surfaces respectively. Similarly, the onset of the second peak is dependent on single crystal surfaces (ca. $0.6 \mathrm{~V}$ at $\mathrm{Ag}(110)$ and ca. $0.9 \mathrm{~V}$ at $\mathrm{Ag}(111)$ surface). Having in mind higher heterogeneity of polycrystalline surface, the broad voltammetric features observed on polycrystalline silver in $0.1 \mathrm{M} \mathrm{NaOH}$, can be assigned to $\mathrm{OH}$ adsorption on surface sites with different surface energies. Similarly, the voltammetric features observed in $11 \mathrm{M}$ solution can be assigned to initial $\mathrm{OH}$ adsorption. So, in general, the formation of underpotential Ag oxide was observed at all studied $\mathrm{NaOH}$ concentrations on polycrystalline silver. Assuming that the processes at most negative potentials are governed only by double layer capacitance effects one can estimate following double layer capacitance values: 55, 65 and $75 \mu \mathrm{F} . \mathrm{cm}^{-2}$ for $0.1,1$ and $11 \mathrm{M} \mathrm{NaOH}$ respectively. Although these differences could be caused by small changes of the electrode roughness from experiment to experiment, this result might also indicate an influence of $\mathrm{NaOH}$ concentration on double layer capacitance. Especially in $11 \mathrm{M} \mathrm{NaOH}$ solution strong ion-ion interactions as well strong deviation of water activity from ideality (Table 1) might influence the electrochemical double layer properties.

To estimate the surface coverage by underpotential Ag oxides, the total exchanged charge densities in the potential region of underpotential Ag oxides at different $\mathrm{NaOH}$ concentrations, are obtained by integration of cyclic voltammograms (only anodic direction) and by correction for double layer capacitance effects (please see Supplementary Information). The results indicate that the $\mathrm{OH}$ coverage on silver is low. Assuming that $400 \mu \mathrm{C} . \mathrm{cm}^{-2}$ [11, [12] corresponds to the charge required for the formation of $\mathrm{OH}$ monolayer on $\mathrm{Ag}$, one can estimate that $\mathrm{OH}$ surface coverage is below 0.18 for all studied concentrations. Additionally, the electrode roughness was estimated based on the charge required for the formation of silver oxide full monolayer in accordance to [12. Similar values 


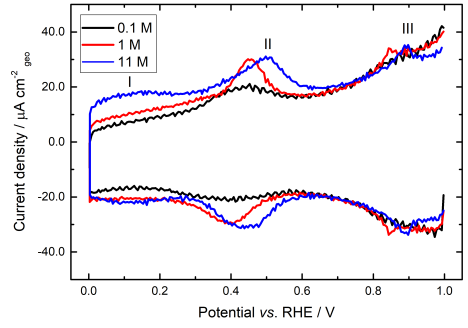

(a)

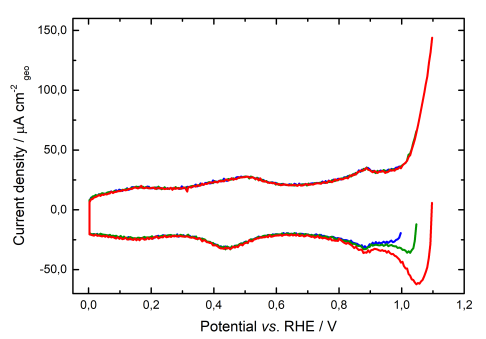

(b)

Figure 1: (a) $\mathrm{CV}$ of polycrystalline silver at different $\mathrm{NaOH}$ concentrations and (b) influence of upper potential limit on voltammetric features in $11 \mathrm{M} \mathrm{NaOH}$. Conditions: NaOH concentrations: $0.1,1$ and $11 \mathrm{M}$, room temperature, sweep rate $200 \mathrm{mVs}^{-1}$, non-prereduced electrode, Ar atmosphere.

of surface roughness were calculated for $0.1 \mathrm{M}$ and $11 \mathrm{M} \mathrm{NaOH}$ solutions (1.69 and 1.76 respectively). Although the here used method could a bit overestimate the surface roughness (the effect of double layer charging/discharging cannot be clearly separated from the charge exchanged due to monolayer formation), this is an indication that the $\mathrm{OH}$ coverage can be even lower. Low $\mathrm{OH}$ coverage values are also in accordance with values based on kinetic Monte Carlo simulation study on on $\mathrm{Ag}(111)$ electrode in $0.1 \mathrm{M} \mathrm{KOH}[13$.

An effect of an upper potential limit extension on voltammetric features on silver was studied for $11 \mathrm{M} \mathrm{NaOH}$ solution only (Figure 1b). As one can see, above $1 \mathrm{~V}$ voltammetric features on silver are no longer reversible and $\mathrm{OH}$ coverage shows further increase.

The ORR current-potential curves at different $\mathrm{NaOH}$ concentrations, together with percentages of hydrogen peroxide detected on the ring electrode and $\mathrm{CVs}$ in $\mathrm{Ar}$ at a rotation rate of $400 \mathrm{rpm}$ are depicted in Figure 2 . ORR in $0.1 \mathrm{M} \mathrm{NaOH}$ shows a very low level of hydrogen peroxide formation in the whole potential region of interest (below $1 \%$, which corresponds to an exchanged number of electrons $\geq 3.98$ ). The polarisation curves in forward and backward directions overlap and no hysteresis is observed. Similar was reported on single 
crystal Ag surfaces [9] and it was assigned to high reversibility of underpotential $\mathrm{Ag}$ oxides formation. The earlier results on polycrystalline Ag disc electrodes (e.g. [14]) report a significant hysteresis between forward and backward directions and lower limiting current densities than in the present study. The authors suggested a higher level and irreversible $\mathrm{OH}$ adsorption on polycrystalline $\mathrm{Ag}$, but our results can rule this out (Figure 1). Our experience indicates that the polishing procedure, the electrode preconditioning and aging effects might have a significant influence on a hysteresis between forward and backward directions as it was also reported in [15].

An increase of $\mathrm{OH}$ concentration (Figure 2b) reflects mainly in two effects: ORR limiting current density is decreasing, and the onset potential shifts towards more positive values. In pure $\mathrm{NaOH}$ level of hydrogen peroxide is low and not significantly dependent on $\mathrm{NaOH}$ concentration. Contrary to pure $\mathrm{NaOH}$ solution the results in impure $\mathrm{NaOH}$ (Figure 2c) show high level of hydroxide peroxide formation. Additionally, while there is only one limiting current plateau in pure $\mathrm{NaOH}$, two plateaus appear in impure $11 \mathrm{M}$ solution (Figure 2c) 11 Two plateaus were also reported in $6.5 \mathrm{M} \mathrm{NaOH}$ solution [4].

The ORR currents, in general, and limiting current densities, in particular, are decreasing due to a decrease of oxygen solubility and of oxygen diffusivity (the change of parameter values with $\mathrm{NaOH}$ concentration is summarized in Table 1). A closer look at peroxide concentration change in $0.1 \mathrm{M}$ solution (Figure 2a shows that the peroxide appears close to onset potentials, but already at a potential of 0.85 , its concentration decreases to zero. An increase of peroxide concentration can be again observed at more negative potentials (below $0.4 \mathrm{~V}$ ). The rotation rate has an influence on detected hydrogen peroxide amount and shows an increase of hydrogen peroxide percentages at higher rotation rate, as it was also observed in the literature ([9]). In $11 \mathrm{M}$ solution (Figure 2b) the sit-

\footnotetext{
${ }^{1}$ It should be mentioned that ORR curves in $11 \mathrm{M}$ solution are obtained at lower sweep rate than in $0.1 \mathrm{M} \mathrm{NaOH}$ in order to reduce the effect of background current on an overall current. This was not necessary for other two $\mathrm{NaOH}$ concentrations.
} 


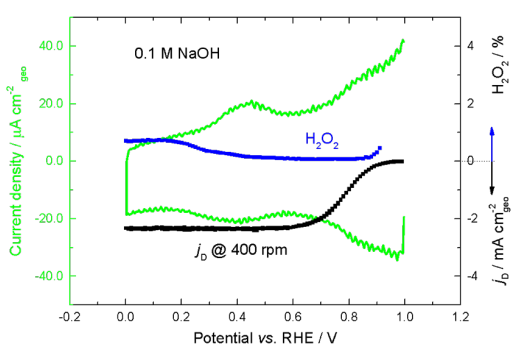

(a)

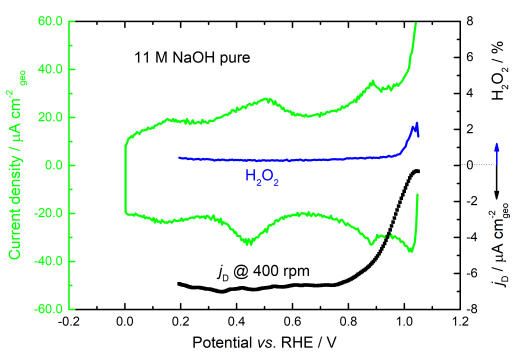

(b)

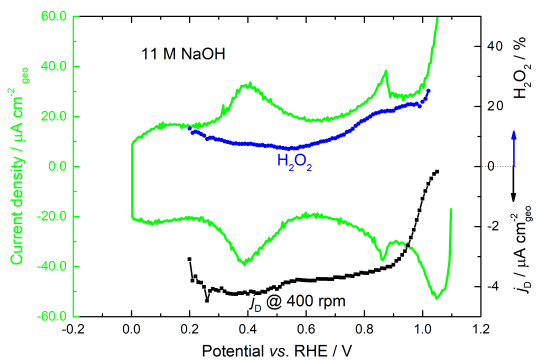

(c)

Figure 2: CVs in oxygen atmosphere (forward and backward directions), percentage of $\mathrm{H}_{2} \mathrm{O}_{2}$ detected on ring electrode and $\mathrm{CV}$ s of silver in $\mathrm{Ar}$ at three different $\mathrm{NaOH}$ concentrations (a) $0.1 \mathrm{M}$ (b) $11 \mathrm{M}$ and (c) $11 \mathrm{M}$ impure. Conditions: sweep rate in Ar $200 \mathrm{mV} \cdot \mathrm{s}^{-1}$, in oxygen $50 \mathrm{mV} \cdot \mathrm{s}^{-1}$ (a), $1 \mathrm{mV} \cdot \mathrm{s}^{-1}$ ( $\mathrm{b}$ and c), room temperature, rotating ring disc electrode, non-prereduced electrodes, rotation rate $400 \mathrm{rpm}$ for $\mathrm{CVs}$ in oxygen and $\mathrm{H}_{2} \mathrm{O}_{2}$ percentages and 0 rpm for CVs in Ar.

uation is quite similar with the level of detected hydrogen peroxide (up to $2 \%$ ). One should also observe that the largest amount of peroxide is formed at low overpotentials. This tendency can be further followed in $11 \mathrm{M}$ impure solution (Figure 2c), where similar to $11 \mathrm{M}$ pure solution the peroxide formation is more favoured at low overpotentials where up to $20 \%$ of peroxide was detected. The results in pure $\mathrm{NaOH}$ solutions confirm previous literature findings on prevailing 4e- pathway for ORR at low $\mathrm{NaOH}$ concentrations [9] as well as an assumption on prevailing 4e- pathway for ORR in highly concentrated alkaline conditions 
[3. However, the data in impure $\mathrm{NaOH}$ demonstrate high influence of impurities on peroxide formation. Having in mind that under industrial conditions the level of impurities is higher than in our "pure" $\mathrm{NaOH}$ solution, high concentration of hydrogen peroxide can be also expected under industrial conditions. Therefore, this information might have significant importance for the understanding of ORR on technical gas diffusion electrodes (GDE). The detection of soluble intermediates (for example hydrogen peroxide) at all studied conditions (potentials as well as $\mathrm{NaOH}$ concentrations) indicates that their further conversion on the disc electrode is not purely mass transport limited as also reported by Savinova et al. 15] on an example of hydrogen peroxide reduction on silver under alkaline conditions.

The open circuit potentials are getting more positive with an increase of $\mathrm{NaOH}$ concentration, while the equilibrium electrode potentials are decreasing (Table 1). The equilibrium electrode potentials are calculated based on the Nernst equation:

$$
E_{\mathrm{O}_{2}, \mathrm{OH}^{-}}=E^{\Theta} \mathrm{O}_{2}, \mathrm{OH}^{-}-E_{\mathrm{H}_{2}, \mathrm{OH}^{-}}-\frac{R T}{2 F} \cdot \ln \frac{a_{\mathrm{H}_{2} \mathrm{O}}}{a_{\mathrm{H}_{2}} \cdot \sqrt{a_{\mathrm{O}_{2}}}}
$$

where the difference between first two terms on the right hand side is $1.222 \mathrm{~V}$ (at $293 \mathrm{~K})$, activity of water $\left(\mathrm{a}_{\mathrm{H}_{2} \mathrm{O}}\right)$ is given in Table 1 and activities of oxygen and hydrogen are expressed as: $\mathrm{a}_{\mathrm{i}}=\mathrm{c}_{\mathrm{i}}\left(\right.$ at $\left.\mathrm{c}_{\mathrm{NaOH}}\right) / \mathrm{c}_{\mathrm{i}}$ (water), $\mathrm{i}=\mathrm{H}_{2}, \mathrm{O}_{2}$. The oxygen concentrations at different $\mathrm{NaOH}$ concentrations are provided in Table 1 . The data for hydrogen concentrations at different alkaline concentrations ${ }^{2}$ are based on [16. The equilibrium electrode potential, as cell potential for $\mathrm{O}_{2} / \mathrm{H}_{2}$ cell, 225 shows no dependence on $\mathrm{OH}$ concentration (the half-reactions are influenced by $\mathrm{OH}$ concentration, but not the overall reaction). Therefore the equilibrium electrode potential shows only the effects of change of activities of components in the overall reaction (water, hydrogen, and oxygen) with $\mathrm{NaOH}$ concentrations (for example water activity is changing between 1 in $0.1 \mathrm{M} \mathrm{NaOH}$ to 0.428 in 11

\footnotetext{
${ }^{2} \mathrm{An}$ assumption was made that hydrogen solubility is not cation depended, but only $\mathrm{OH}$ concentration.
} 
$\mathrm{M} \mathrm{NaOH})$. As already mentioned the open circuit potential is increasing with an increase of $\mathrm{NaOH}$ concentration; as a consequence, the effective overpotentials for ORR are decreasing with an increase of $\mathrm{NaOH}$ concentration.

Table 1: An overview of kinetic and other parameters for ORR on silver in different $\mathrm{NaOH}$ concentrations

\begin{tabular}{|c|c|c|c|}
\hline Parameters & $0.1 \mathrm{M}$ & $1 \mathrm{M}$ & $11 \mathrm{M}$ \\
\hline Apparent kinetic constant/ $\mathrm{ms}^{-1}$ & $4 \cdot 10^{-9 *}$ & $5 \cdot 10^{-9 *}$ & $3.25 \cdot 10^{-7 *}$ \\
\hline Equilibrium potential vs. RHE / V & $1.222^{* *}$ & $1.217^{* *}$ & $1.163^{* *}$ \\
\hline Open circuit potential vs. RHE / V & $0.960 \mathrm{~V} \pm 0.01$ & $0.975 \mathrm{~V} \pm 0.01$ & $1.03 \mathrm{~V} \pm 0.01$ \\
\hline Oxygen concentration/ mol.m $\mathrm{m}^{-3}$ & $1.18[17$ & $0.95[17$ & $8.58 \cdot 10^{-3}$ 18. 19] \\
\hline $\mathrm{NaOH}$ density/ kg.m ${ }^{-3}$ & 1002 & 1040 & 1350 \\
\hline $\mathrm{NaOH}$ kinematic viscosity $/ \mathrm{m}^{2} \cdot \mathrm{s}^{-1}$ & $1.01 \cdot 10^{-6} 20$ & $1.1 \cdot 10^{-6}[20]$ & $1.28 \cdot 10^{-5}[20]$ \\
\hline Water activity / - & 1 & 0.967 20] & 0.428 20] \\
\hline $\mathrm{OH}$ activity / - & 0.078 20] & 0.67 20] & 69.5 20] \\
\hline Oxygen diffusivity $/ \mathrm{m}^{2} \cdot \mathrm{s}^{-1}$ & $1.9 \cdot 10^{-9}[17$ & $1.2 \cdot 10^{-9}[17$ & $7.13 \cdot 10^{-10 *}$ \\
\hline
\end{tabular}

accordance with eq. 1 .

The Tafel plots for ORR on silver at two $\mathrm{NaOH}$ concentrations (1 $\mathrm{M}$ and 11 M) both as "pure" and "impure" are displayed in Figure 3 As one can see the higher level of impurities in $1 \mathrm{M}$ solution shows no apparent effect on the reaction mechanism, but it is reducing the number of exchanged electrons (the level of detected hydrogen peroxide was higher in impure (up to ca $8 \%$ ) than in pure solution at $400 \mathrm{rpm}$ ). The Tafel slopes in both pure and impure solutions are similar, with somewhat lower values (ca. $94 \mathrm{mV} \cdot \mathrm{dec}^{-1}$ ) at lower overpotentials and higher values at higher overpotentials (ca. $108 \mathrm{mV} \cdot \mathrm{dec}^{-1}$ ). Similar values were obtained for $0.1 \mathrm{M}$ solution (please see the SI). Wiberg et al. 21] determined only one Tafel slope value of $90 \mathrm{mV} \cdot \mathrm{dec}^{-1}$ on polycrystalline silver in $0.1 \mathrm{M} \mathrm{KOH}$. They assumed that two Tafel slope values reported in literature were artefacts of non-compensated Ohmic drop resistance in earlier literature. However, they have shown only the data and Tafel slope value at lower overpotentials (which corresponds well to the value obtained in the present 
manuscript); closer inspection of their data indicate an increase of Tafel slope at higher overpotentials. Blizanac et al. 9] determined two Tafel slope values at lower and higher overpotentials and explained it in terms of potential depen$\mathrm{NaOH}$ show the ORR reaction onsets at more positive potentials than at lower 
$\mathrm{NaOH}$ concentration. $11 \mathrm{M} \mathrm{NaOH}$ solution is highly concentrated and highly non-ideal. Currently there is a little information on kinetics of electrochemical reactions under such conditions. Further studies are needed to understand the influence of these non-idealities on electrochemical double layer structure and its impact on kinetics.

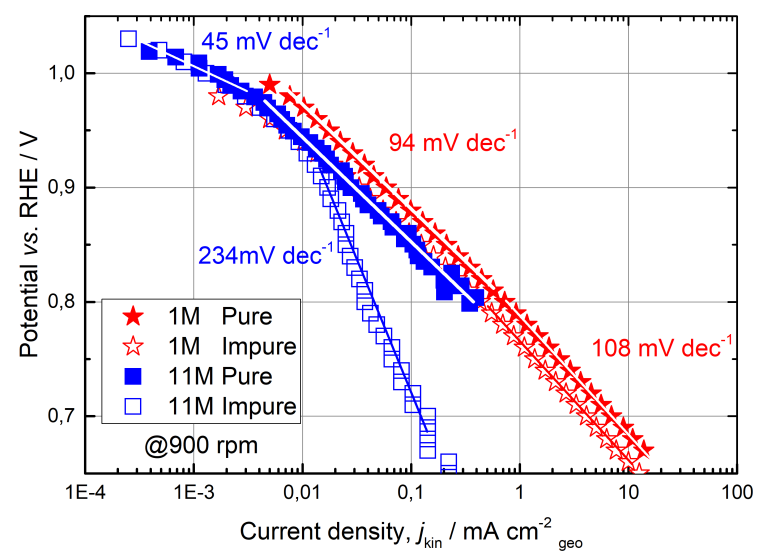

Figure 3: Tafel plots for ORR on silver at different conditions on non-prereduced electrodes in different $\mathrm{NaOH}$ concentrations. Conditions: sweep rate $50 \mathrm{mV} \cdot \mathrm{s}^{-1}$ or $1 \mathrm{mV} \cdot \mathrm{s}^{-1}(11 \mathrm{M})$, room temperature, rotation rate $900 \mathrm{rpm}$.

The ORR kinetics was studied further by NFRA. NFRA is based on a concept of a generalized nonlinear frequency response function and can be considered as an extrapolation of a linear electrochemical impedance spectroscopy to a nonlinear range 22. We have already demonstrated that NFRA can discriminate between different kinetics mechanisms [Bensmann et al [23] and we also demonstrated its application in theory and experiment on an example of simple reversible mass transfer limited reaction [7, 22. Therefore in the present publication, we report for the first time NFR spectra for ORR on a polycrystalline silver electrode (Figure 4). NFRA was performed in the potential region characterized by similar Tafel slope values at different $\mathrm{NaOH}$ concentrations (ca. 94 $\left.\mathrm{mV} \cdot \mathrm{dec}^{-1}\right)$. 


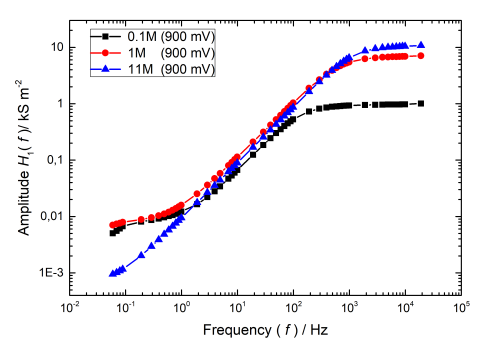

(a)

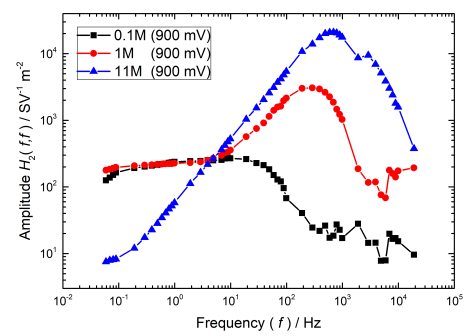

(c)

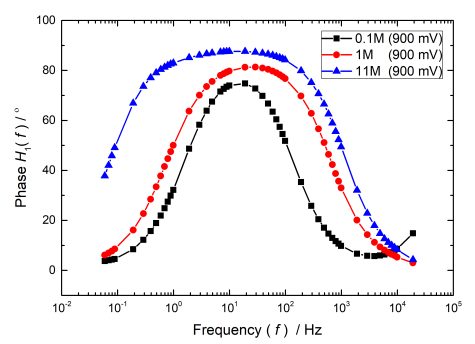

(b)

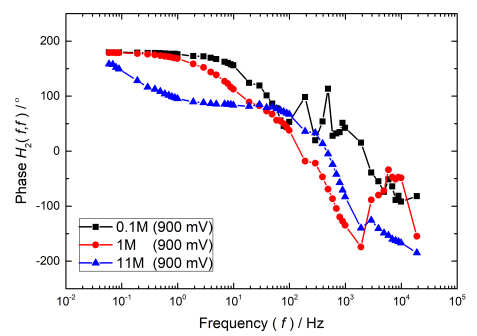

(d)

Figure 4: Influence of $\mathrm{NaOH}$ concentration on experimental first (electrochemical admittance) and second order frequency response functions for ORR on silver. Conditions: potential 0.9 $\mathrm{V}$, rotation rate $1600 \mathrm{rpm}$, room temperature, amplitude $30 \mathrm{mV}$ rms.

In order to facilitate the interpretation of NFRA, we developed a facile analytical model to simulate NFR spectra implemented in the MATLAB. This model involves a simple irreversible electrochemical reaction and diffusion. The appearance of almost single Tafel slope value at lower $\mathrm{NaOH}$ concentrations, which is relatively close to theoretically expected Tafel slope of $116 \mathrm{mV} \cdot \mathrm{dec}^{-1}$ for a 1st electron transfer as a rate limiting step indicates that in most simplified form the ORR kinetics on silver under alkaline conditions can be represented as:

$$
\begin{gathered}
\mathrm{O}_{2 \text { (diffusion) }} \stackrel{\mathrm{k}_{\text {diff }}}{\longrightarrow} \mathrm{O}_{2 \text { (surface) }} \\
\mathrm{O}_{2 \text { (surface) }}+\mathrm{e}^{-} \stackrel{\mathrm{k}_{\mathrm{app}}}{\longrightarrow} \text { products }
\end{gathered}
$$


which allows us further to express the reaction rate in the form of:

$$
r(t)=k_{\mathrm{app}} \cdot C_{\mathrm{O}_{2(\text { surface })}} \cdot e^{\left(\frac{-\alpha F}{R T} \eta\right)}
$$

and the current density is calculated as :

$$
j=-4 \cdot F \cdot r(t)
$$

where $\eta=\mathrm{E}-\mathrm{E}_{\mathrm{O}_{2}, \mathrm{OH}^{-}}, \mathrm{k}_{\mathrm{app}}$ is an apparent heterogeneous rate constant in $\mathrm{m} . \mathrm{s}^{-1}, \mathrm{C}_{\mathrm{O} 2 \text { (surface) }}$ is the concentration at the electrode surface in mol. $\mathrm{m}^{-3}, \alpha$ is transfer coefficient, $\mathrm{F}$ is the Faraday constant $\left(96485 \mathrm{C}^{\mathrm{mol}}{ }^{-1}\right)$, $\mathrm{R}$ universal gas constant $\left(8.314 \mathrm{~J} \mathrm{~mol}^{-1} \cdot \mathrm{K}^{-1}\right)$ and $\mathrm{T}$ temperature in $\mathrm{K}(293 \mathrm{~K})$. The mass transport description is in accordance with the hydrodynamics of a rotating disc electrode [22].

$$
\frac{\partial C_{\mathrm{O}_{2}}(z, t)}{\partial t}=D_{\mathrm{O}_{2}} \cdot \frac{\partial^{2} C_{\mathrm{O}_{2}}(z, t)}{\partial z^{2}}
$$

with boundary conditions :

$$
\begin{gathered}
\left.D_{\mathrm{O}_{2}} \cdot \frac{\partial C_{\mathrm{O}_{2}}(z, t)}{\partial t}\right|_{z=0}=+r(t) \\
C_{\mathrm{O}_{2}}\left(\delta_{D}, t\right)=C_{\mathrm{O}_{2}(\text { bulk })}
\end{gathered}
$$

where

$$
\delta_{D}=1.61 \cdot D^{1 / 3} \cdot \nu^{1 / 6} \cdot \omega^{-1 / 2}
$$

is the thickness of diffusion layer for oxygen at rotation speed, $\omega$, of the rotating disc electrode in solution of viscosity, $\nu$.

The charge balance at the electrode is given as:

$$
C_{d l} \cdot \frac{d \eta(t)}{d t}=j(t)+4 \cdot F \cdot r(t)
$$

where overpotential, $\eta(t)$, is given as:

$$
\eta(t)=E(t)-E^{\theta}-R_{\Omega} \cdot j(t)
$$

One has to further define the non-dimensional input and output variables. The input is potential $\mathrm{E}(\mathrm{t})$, periodically changing around steady state, $\mathrm{E}_{\mathrm{s}}$. It is given as:

$$
E(t)=E_{s} \cdot(1+A \cdot \cos (f \cdot t))
$$


with the non-dimensional input defined as:

$$
\tilde{E}=\frac{E(t)-E_{s}}{E_{s}}=A \cdot \cos (f \cdot t)=\frac{A}{2} \cdot\left(e^{(j f t)}+e^{(-j f t)}\right)
$$

The output signal is the current density $j(t)$. Similarly, the non-dimensional current density, $\tilde{j}$ is defined as:

$$
\begin{aligned}
\tilde{j}=\frac{j(t)-j_{s}}{j_{s}}= & \frac{A}{2} \cdot\left(G_{1 j}(f) \cdot e^{(i f t)}+G_{1 j}(-f) \cdot e^{(-i f t)}\right) \\
+\left(\frac{A}{2}\right)^{2} \cdot\left(G_{2 j}(f, f) \cdot e^{(2 i f t)}\right. & +2 G_{2 j}(f,-f) \cdot e^{0} \\
& \left.+G_{2 j}(-f,-f) \cdot e^{(-2 i f t)}\right) \ldots
\end{aligned}
$$

where the function $G_{1 j}(\mathrm{f})$ is the first-order frequency response function of the system and it corresponds to electrochemical admittance. $G_{2 j}(\mathrm{f}, \mathrm{f})$ and so on are higher order frequency response functions. They contain information on system non-linearities. In the present contribution only the first and the second order frequency response functions were considered. The analytical expressions of these frequency response functions are obtained based on method explained in our previous publications 22]. Since the derived frequency response functions are dimensionless, in order to compare them with experiments they were converted into their dimensional forms denoted by the symbol " $\mathrm{H}$ ". (please see the Supplementary Information) The dynamic model described above was firstly used to simulate steady state responses for different $\mathrm{NaOH}$ concentrations. Only fitting parameters were apparent rate constants. Additionally in $11 \mathrm{M} \mathrm{NaOH}$ oxygen diffusivity was also considered as a fitting parameter. This was necessary in order to reproduce experimentally observed limiting current densities in $11 \mathrm{M} \mathrm{NaOH}$ by fixing at the same time oxygen solubility value [18. It could be shown that despite model simplicity quite good description of experimental data at a rotation rate of $400 \mathrm{rpm}$ and at different $\mathrm{NaOH}$ concentrations (only pure $\mathrm{NaOH}$ was considered) (please see Supplementary Information) was obtained. The apparent rate constants based on this simplified model are summarized in Table I. The apparent rate constant is almost not changing at low $\mathrm{NaOH}$ concentrations, but there is a significant change compared to the value in 
$11 \mathrm{M} \mathrm{NaOH}$ solution. It should be mentioned that the apparent rate constant in $11 \mathrm{M} \mathrm{NaOH}$ refers to second Tafel slope region $\left(94 \mathrm{mV} \mathrm{dec}{ }^{-1}\right)$. Similar was observed by Chatenet et al. [3] who referring to ORR on platinum under similar conditions, where such effect was not observed, hypothesized that the observed differences in reaction rates were caused by different influence of $\mathrm{NaOH}$ concentration on surface oxide formation on silver and platinum. The authors based on their results assumed that compared to platinum there is no significant oxide building on silver.

The same model was used further to simulate nonlinear frequency response at three different concentrations $(0.1 \mathrm{M}, 1 \mathrm{M}$ and $11 \mathrm{M})$. The simulated first order frequency response functions (FRF) (electrochemical admittance) and the second-order FRFs at three $\mathrm{NaOH}$ concentrations are shown in Figure 5 As one can see the simple model and the parameter values based on "steady state" responses ( $\mathrm{k}_{\mathrm{app}}$ and $\mathrm{O}_{2}$ diffusivity; double layer capacitance values were extracted from the data in Figure 1, please see Table 1) can quite well capture the dynamics of the linear response. Previous data [3] on electrochemical impedance spectroscopy on $\mathrm{Ag} / \mathrm{C}$ electrodes in $1 \mathrm{M} \mathrm{NaOH}$ solutions were characterized by low frequency inductive loop. This feature was not observed under present conditions, indicating that the first electron transfer is responsible for RDS. Our experimental data do also not indicate a pseudo-inductive behaviour.For this there are two possible explanations, either the pseudo-inductive loop appears at lower frequencies which were not studied under present conditions, or the appearance of the pseudo-inductive loop is related to different structure of the electrode in the literature and the present study. For the second-order FRF, simulated data at $0.1 \mathrm{M} \mathrm{NaOH}$ shows very good qualitative agreement to experimental data. The simulated and experimental data at two higher concentrations show larger deviations to experimental data especially at higher frequencies. It is interesting that the simulated phase of the second order frequency response 345 function shows very good qualitative agreement with the experimental values. These results are very promising, but they also advocate a necessity of a more complex model for explanation of ORR. 


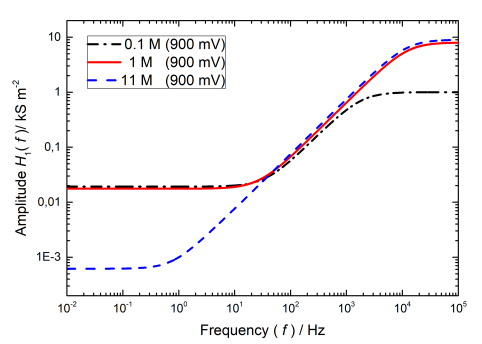

(a)

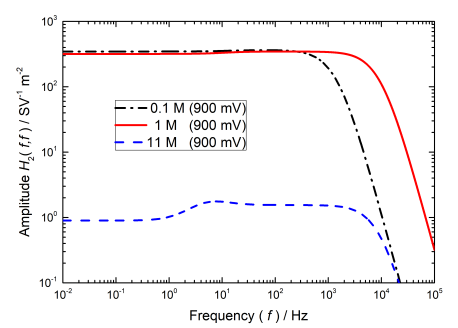

(c)

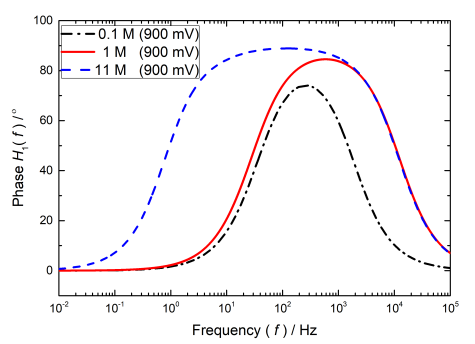

(b)

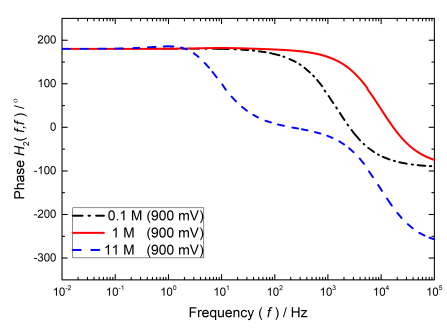

(d)

Figure 5: Influence of $\mathrm{NaOH}$ concentration on simulated first (electrochemical admittance) and second-order frequency response functions for ORR on silver. Conditions: potential 0.9 $\mathrm{V}$, rotation rate $1600 \mathrm{rpm}$, room temperature, parameters in Table I.

\section{Conclusion}

The ORR on silver at different $\mathrm{NaOH}$ concentrations was studied. It was shown that underpotential Ag oxides are formed in all studied solutions. The voltammetric features in argon are well expressed, especially in $11 \mathrm{M}$ solution, while peaks are broader at lower $\mathrm{NaOH}$ concentrations. The integrated charge in the anodic sweep direction, after double layer capacitance subtraction, indicates low $\mathrm{OH}$ coverage. The Tafel slopes in different $\mathrm{NaOH}$ solutions are somewhat potential range dependent, varying from ca. $94 \mathrm{mV} \cdot \mathrm{dec}^{-1}$ at low overpotentials to ca. $108 \mathrm{mV} \cdot \mathrm{dec}^{-1}$ at high overpotentials in $1 \mathrm{M} \mathrm{NaOH}$ concentrations. Similar values were obtained in $0.1 \mathrm{M}$ solution. In $11 \mathrm{M} \mathrm{NaOH}$, a low Tafel slope is observed at low overpotentials and ca. $94 \mathrm{mV} \cdot \mathrm{dec}^{-1}$ at higher overpotentials. Additionally in impure $11 \mathrm{M} \mathrm{NaOH}$ additional high Tafel slope 
360 trations, the impurities do not change the reaction mechanism but reduce the number of exchanged electrons. At higher $\mathrm{NaOH}$ concentrations, changes in RDS due to impurities take place. In general, the amount of soluble reaction intermediate was increasing with an increase level of impurities. The appearance of soluble reaction intermediate might be highly relevant for ORR reduction in 3-dimensional GDE electrodes and can help to understand limitations under technical conditions. The NFR spectra indicate a higher sensitivity of this method to kinetic mechanism discrimination which will be utilized further in our future studies.

\section{Acknowledgment}

The authors gratefully acknowledge the financial support by German Research Foundation (Deutsche Forschungsgemeinschaft, DFG) within the framework of the project Grant VI 845/1-1. L.A.Z and M.P are grateful for the financial support by Ministry of Education, Science and Technological Development of the Republic of Serbia (Project Num.172022). L.A.Z is grateful to DFG for financial support of his research stay at the Max Planck Institute for Dynamics of Complex Technical Systems, Magdeburg, Germany in the framework of DFG research Unit FOR2397. 


\section{List of symbols}

$\begin{array}{lll}\text { Symbol } & \text { Name } & \text { Value, Unit } \\ \mathrm{s} & \text { Steady state } & \\ \mathrm{E} & \text { Electrode potential } & \mathrm{V} \\ \eta & \text { Overpotential } & \mathrm{V} \\ \mathrm{j} & \text { Current density } & \mathrm{A} / \mathrm{m}^{2} \\ \mathrm{~F} & \text { Faraday constant } & 96485 \mathrm{C} / \mathrm{mol} \\ \mathrm{E}^{\theta} & \text { Standard electrode potential } & \mathrm{V} \\ \mathrm{R} & \text { Universal gas constant } & 8.314 \mathrm{~J} / \mathrm{mol} / \mathrm{K} \\ \mathrm{t} & \text { Time } & \mathrm{s} \\ \mathrm{r} & \text { Reaction rate } & \mathrm{mol} / \mathrm{m}^{2} . \mathrm{s} \\ k_{a p p} & \text { Kinetic constant } & \mathrm{m} / \mathrm{s} \\ \alpha & \text { Transfer coefficient } & \\ \mathrm{T} & \text { Temperature } & \mathrm{K} \\ \omega & \text { Electrode rotation rate } & \mathrm{rad} / \mathrm{s} \\ \mathrm{f} & \text { Frequency } & \mathrm{Hz} \\ \mathrm{D} & \text { Diffusivity } & \mathrm{m}{ }^{2} / \mathrm{s} \\ \nu & \text { NaOH kinematic viscosity } & \mathrm{m}{ }^{2} / \mathrm{s} \\ C_{d l} & \text { Double layer capacitance } & \mathrm{F} / \mathrm{m}^{2} \\ \mathrm{~A} & \text { Amplitude of change } & \mathrm{V} \\ \mathrm{G} & \text { Non-dimensional frequency response function } & \\ \mathrm{H} & \text { Dimensional frequency response function } & \mathrm{V} \text { or A/V }\end{array}$

\section{References}

[1] C. Song, J. Zhang, Electrocatalytic Oxygen Reduction Reaction,

口 Springer London, London, 2008, Ch. 2, pp. 89-134. doi:10.1007/ 978-1-84800-936-3_2

URL https://doi.org/10.1007/978-1-84800-936-3_2

口 [2] H. Erikson, A. Sarapuu, K. Tammeveski, Oxygen reduction reaction on silver catalysts in alkaline media: a minireview, ChemElectroChem 6 (1)

口 (2019) 73-86. arXiv:https://onlinelibrary.wiley.com/doi/pdf/10. 1002/celc.201800913, doi:10.1002/celc.201800913.

390 uRL https://onlinelibrary.wiley.com/doi/abs/10.1002/celc. 201800913 
[3] M. Chatenet, L. Genies-Bultel, M. Aurousseau, R. Durand, F. Andol-

口 fatto, Oxygen reduction on silver catalysts in solutions containing various concentrations of sodium hydroxide - comparison with platinum, Journal of Applied Electrochemistry 32 (10) (2002) 1131-1140. doi:10.1023/A: 1021231503922

URL https://doi .org/10.1023/A:1021231503922

n [4] P. K. Adanuvor, R. E. White, Oxygen reduction on silver in 6.5m caustic soda solution, Journal of The Electrochemical Society 135 (10) (1988) 25092517. arXiv:http://jes.ecsdl.org/content/135/10/2509.full.pdf+ html, doi:10.1149/1.2095367. URL http://jes .ecsdl.org/content/135/10/2509.abstract

口 [5] S. Pinnow, N. Chavan, T. Turek, Thin-film flooded agglomerate model for silver-based oxygen depolarized cathodes, Journal of Applied Electrochemistry 41 (9) (2011) 1053-1064. doi:10.1007/s10800-011-0311-2. URL https://doi .org/10.1007/s10800-011-0311-2

[ [6] D. Šepa, M. Vojnovíc, A. Damjanovic, Oxygen reduction at silver electrodes in alkaline solutions, Electrochimica Acta 15 (8) (1970) 1355 1366. doi:https://doi.org/10.1016/0013-4686(70)80055-X. $001346867080055 \mathrm{X}$

[7] V. V. Panić, T. R. Vidaković-Koch, M. Andrić, M. Petkovska, K. Sundmacher, Nonlinear frequency response analysis of the ferrocyanide oxi-

1 dation kinetics. part ii. measurement routine and experimental valida415 tion, The Journal of Physical Chemistry C 115 (35) (2011) 17352-17358. arXiv:https://doi.org/10.1021/jp201300a, doi:10.1021/jp201300a URL https://doi.org/10.1021/jp201300a

q [8] G. Orozco, M. C. Pérez, A. Rincón, C. Gutiérrez, Adsorption and electrooxidation of carbon monoxide on silver, Langmuir 14 (21) (1998) 6297-6306. 
arXiv:https://doi.org/10.1021/la980157t, doi:10.1021/la980157t,

URL https://doi .org/10.1021/la980157t

[ [9] B. B. Blizanac, P. N. Ross, N. M. Marković, Oxygen reduction on silver lowindex single-crystal surfaces in alkaline solution: Rotating ring diskag(hkl) studies, The Journal of Physical Chemistry B 110 (10) (2006) 4735-4741, pMID: 16526709. arXiv:https://doi.org/10.1021/jp056050d doi:10. 1021/jp056050d. URL https://doi.org/10.1021/jp056050d

[10] E. R. Savinova, A. Scheybal, M. Danckwerts, U. Wild, B. Pettinger, K. Doblhofer, R. Schlögl, G. Ertl, Structure and dynamics of the interface between a ag single crystal electrode and an aqueous electrolyte, Faraday Discuss. 121 (2002) 181-198. doi:10.1039/B110843N. URL http://dx.doi.org/10.1039/B110843N

[11] Q. Lu, J. Rosen, Y. Zhou, G. S. Hutchings, Y. C. Kimmel, J. G. Chen, F. Jiao, A selective and efficient electrocatalyst for carbon dioxide reduction., Nature communications 5 (2014) 3242.

[12] J. G. Becerra, R. Salvarezza, A. Arvia, The role of a slow phase formation घ process in the growth of anodic silver oxide layers in alkaline solutionsi. electroformation of ag(i) oxide layer, Electrochimica Acta 33 (10) (1988) 1431 - 1437. doi:https://doi.org/10.1016/0013-4686(88)80135-X. URL http://www.sciencedirect.com/science/article/pii/ $001346868880135 \mathrm{X}$

[13] S. Liu, M. G. White, P. Liu, Oxygen reduction reaction on घ $\operatorname{ag}(111)$ in alkaline solution: A combined density functional theory and kinetic monte carlo study, ChemCatChem 10 (3) (2018)

445 a 540-549. arXiv:https://www.onlinelibrary.wiley.com/doi/pdf/10. 1002/cctc.201701539, doi:10.1002/cctc.201701539.

【URL https://www.onlinelibrary.wiley.com/doi/abs/10.1002/cctc. 201701539 
[14] P. Singh, D. Buttry, Comparison of oxygen reduction reaction at silver nanoparticles and polycrystalline silver electrodes in alkaline solution, The Journal of Physical Chemistry C 116 (2012) 1065610663. doi:10.1021/ jp301676n.

[15] E. Savinova, S. Wasle, K. Doblhofer, Structure and activity relations

1 in the hydrogen peroxide reduction at silver electrodes in alkaline naf/naoh electrolytes, Electrochimica Acta 44 (8) (1998) 1341 - 1348. doi:https://doi.org/10.1016/S0013-4686(98)00256-4.

口 URL http://www.sciencedirect.com/science/article/pii/ S0013468698002564

[16] P. Ruetschi, R. F. Amlie, Solubility of hydrogen in potassium hydroxide and sulfuric acid. salting-out and hydration, The Journal of Physical Chemistry 70 (3) (1966) 718-723. arXiv:https://doi.org/10.1021/j100875a018 doi:10.1021/j100875a018. URL https: //doi .org/10.1021/j100875a018

[17] W. Jin, H. Y. Du, S. Zheng, H. Xu, Y. Zhang, Comparison of the oxygen reduction reaction between naoh and koh solutions on a pt electrode: the electrolyte-dependent effect., The journal of physical chemistry. B 11419 (2010) 6542-8.

[18] M. Chatenet, M. Aurousseau, R. Durand, Comparative methods for gas

diffusivity and solubility determination in extreme media: Application to molecular oxygen in an industrial chlorinesoda electrolyte, Industrial \& Engineering Chemistry Research 39 (8) (2000) 3083-3089. arXiv:https: //doi.org/10.1021/ie000044g, doi:10.1021/ie000044g URL https://doi .org/10.1021/ie000044g

[19] M. Chatenet, M. Aurousseau, R. Durand, Electrochemical measure475 ment of the oxygen diffusivity and solubility in concentrated alkaline घ media on rotating ring-disk and disk electrodesapplication to industrial chlorine-soda electrolyte, Electrochimica Acta 45 (17) (2000) 2823 - 2827. 


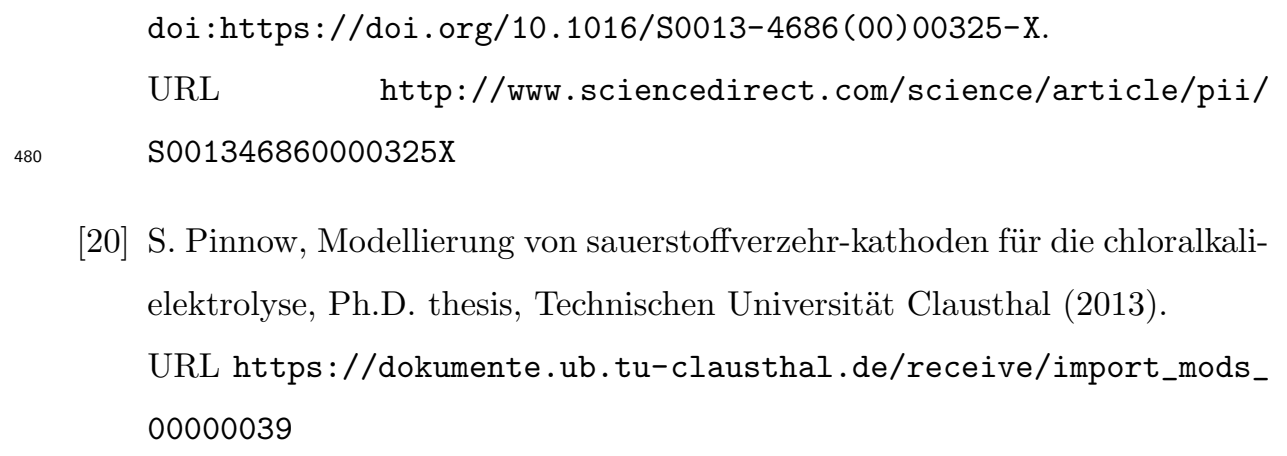

[20] S. Pinnow, Modellierung von sauerstoffverzehr-kathoden für die chloralkalielektrolyse, Ph.D. thesis, Technischen Universität Clausthal (2013). URL https://dokumente.ub.tu-clausthal.de/receive/import_mods_ 00000039 a of the oxygen reduction activity on silver a rotating disc elec1 trode study, Fuel Cells 10 (4) (2010) 575-581. arXiv:https: //onlinelibrary.wiley.com/doi/pdf/10.1002/fuce.200900136, doi:10.1002/fuce.200900136. URL https://onlinelibrary.wiley.com/doi/abs/10.1002/fuce. 200900136

[22] T. R. Vidaković-Koch, V. V. Panić, M. Andrić, M. Petkovska, K. Sundmacher, Nonlinear frequency response analysis of the ferrocyanide oxidation kinetics. part i. a theoretical analysis, The Journal of Physical Chemistry C 115 (35) (2011) 17341-17351. arXiv:https://doi.org/10.1021/ jp201297v, doi:10.1021/jp201297v URL https://doi.org/10.1021/jp201297v

[23] B. Bensmann, M. Petkovska, T. Vidaković-Koch, R. Hanke-Rauschenbach, K. Sundmacher, Nonlinear frequency response of electrochemical methanol 500 oxidation kinetics: A theoretical analysis, Journal of The Electrochemi-

口 cal Society 157 (9) (2010) B1279-B1289. arXiv:http://jes.ecsdl.org/ content/157/9/B1279.full.pdf+html, doi:10.1149/1.3446836

URL http://jes.ecsdl .org/content/157/9/B1279. abstract 